\title{
Thermal, atmospheric and ionospheric anomalies around the time of the Colima M7.8 earthquake of 21 January 2003
}

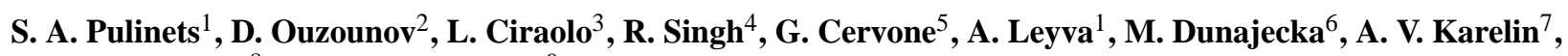 \\ K. A. Boyarchuk ${ }^{8}$, and A. Kotsarenko ${ }^{9}$ \\ ${ }^{1}$ Institute of Geophysics, UNAM, Mexico City, Mexico \\ ${ }^{2}$ NASA Goddard Space Flight Center/SSAI, Greenbelt, Maryland, USA \\ ${ }^{3}$ Institute of Applied Physics "Nello Carrara", CNR, Florence, Italy \\ ${ }^{4}$ Department of Civil Engineering, Indian Institute of Technology, Kanpur, India \\ ${ }^{5}$ George Mason University, Fairfax, Virginia, USA \\ ${ }^{6}$ Institute of Geography, UNAM, Mexico City, Mexico \\ ${ }^{7}$ IZMIRAN, Russian Academy of Sciences, Troitsk, Russia \\ ${ }^{8}$ NPP VNIIEM, Moscow Russia \\ ${ }^{9}$ Institute of Geosciences, UNAM, Mexico
}

Received: 17 May 2005 - Revised: 15 December 2005 - Accepted: 27 January 2006 - Published: 19 May 2006

\begin{abstract}
The paper examines the possible relationship of anomalous variations of different atmospheric and ionospheric parameters observed around the time of a strong earthquake $\left(\mathbf{M}_{w}\right.$ 7.8) which occurred in Mexico (state of Colima) on 21 January 2003. These variations are interpreted within the framework of the developed model of the Lithosphere-Atmosphere-Ionosphere coupling. The main attention is focused on the processes in the near ground layer of the atmosphere involving the ionization of air by radon, the water molecules' attachment to the formed ions, and the corresponding changes in the latent heat. Model considerations are supported by experimental measurements showing the local diminution of air humidity one week prior to the earthquake, accompanied by the anomalous thermal infrared (TIR) signals and surface latent heat flux (SLHF) and anomalous variations of the total electron content (TEC) registered over the epicenter of the impending earthquake three days prior to the main earthquake event. Statistical processing of the data of the GPS receivers network, together with various other atmospheric parameters demonstrate the possibility of an early warning of an impending strong earthquake.
\end{abstract}

Keywords. Atmospheric composition and structure (Ion chemistry of the atmosphere) - Meteorology and atmospheric dynamics (Atmospheric electricity) - Ionosphere (Ionosphere-atmosphere interactions)

Correspondence to: S. A. Pulinets

(pulse@geofisica.unam.mx)

\section{Introduction}

The 2003 Colima (Tecoman) earthquake occurred near the junction of three tectonic plates: the North American plate to the northeast, the Rivera plate to the northwest, and the Cocos plate to the south. Both the Rivera and the Cocos plates are being subducted beneath the North American plate (Bandy et al., 2000). A tectonic configuration is shown in Fig. 1a. The earthquake occurred in a seismic gap region located in between the rupture zones of the Manzanillo earthquake $\left(\mathrm{M}_{w}\right.$ 8.0) of 1995 and the Colima 1973 earthquake $\left(\mathbf{M}_{w}\right.$ 7.6) (see Fig. 1b) (Singh et al., 2003). According to the US Geological Survey's National Earthquake Information Center (NEIC), the earthquake struck at 8:06 p.m. on Tuesday evening (local time). Table 1 shows the different locations of the hypocenter and focal mechanisms given by various agencies. According to EERI (Earthquake Engineering Research Institute) Special Earthquake (http://www.eeri. org/lfe/pdf/mexico_colima_EERI_preliminary.pdf), 21 people lost their lives, more than 500 were injured and 13493 residential buildings were damaged.

Recent studies have clearly demonstrated the existence of anomalous variations within the ionosphere over the epicentral zone several days prior to the earthquake events $(\mathrm{Pu}-$ linets, 1998; Liu et al., 2000; Pulinets et al., 2003). It has been proved statistically that anomalous variations in the ionosphere appear within the time interval 1-5 days prior to the earthquake events (Liu et al., 2004). The conclusion on the lead time of the ionospheric anomalies, of the order of 5 days, was supported by the empirical results obtained

Published by Copernicus GmbH on behalf of the European Geosciences Union. 


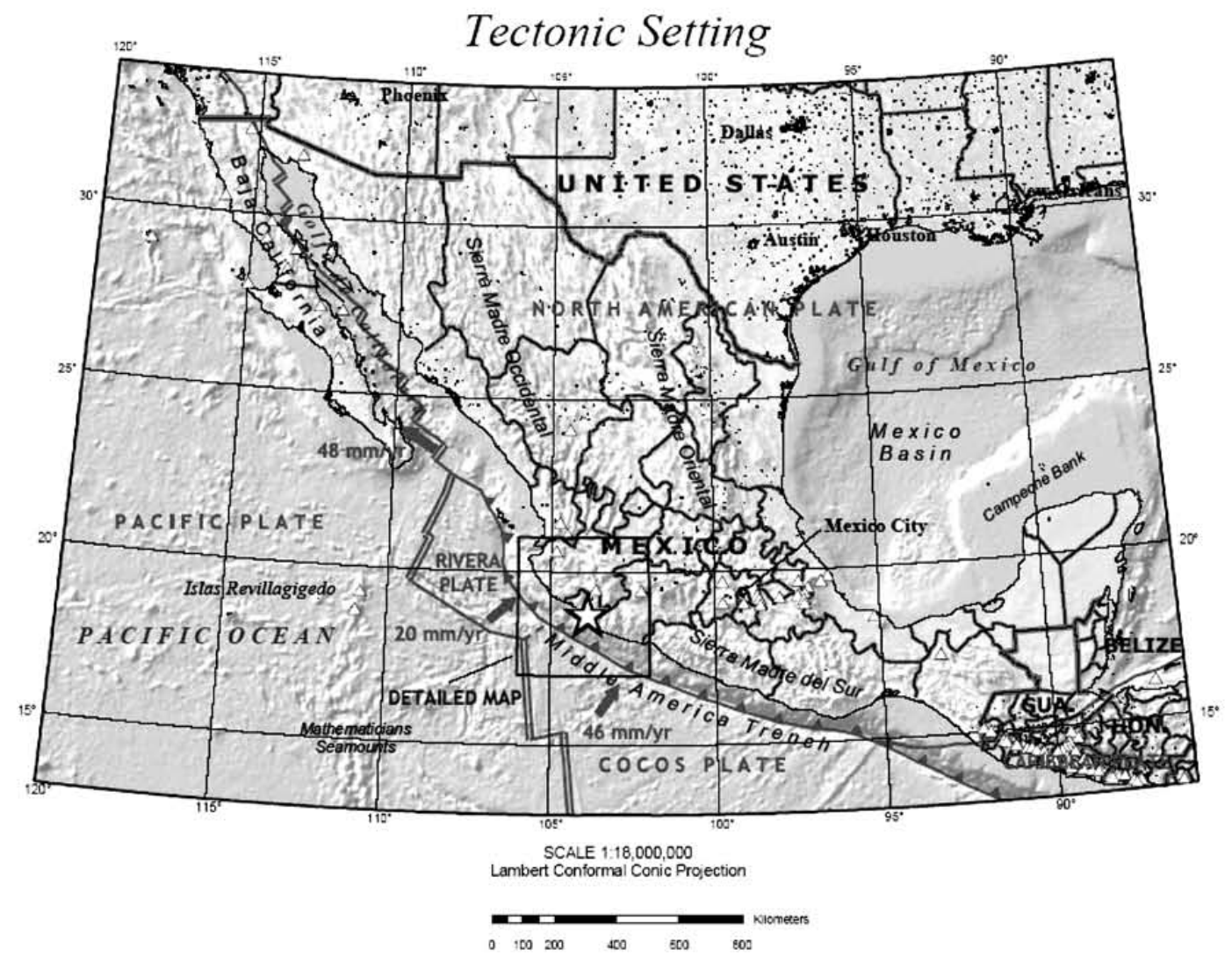

a)

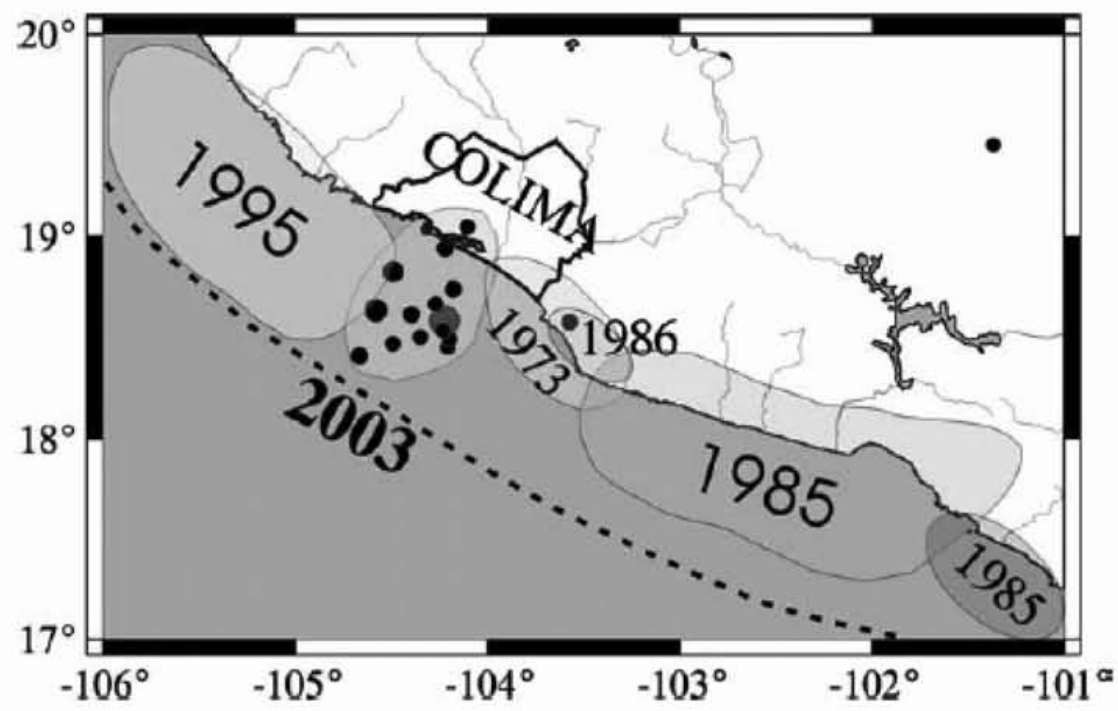

b)

Fig. 1. (a) Tectonic plates' configuration in Central America (http://earthquake.usgs.gov/eqcenter/eqarchives/poster/2003/20030122_image. php). (b) Approximate location of rupture planes of subduction zone events since 1973 (http://www.ssn.unam.mx/Colima030121/index. html). 
Table 1. Different locations and focal mechanism.

\begin{tabular}{llllll}
\hline Agency & $\mathrm{M}_{w}$ & $\begin{array}{l}\text { Hypocenter } \\
\text { Coordinates }\end{array}$ & $\begin{array}{l}\text { Hypocenter } \\
\text { Depth }(\mathrm{km})\end{array}$ & $\begin{array}{l}\text { Strike/Dip/Slip } \\
\text { (fault plane) }\end{array}$ & Reference \\
\hline USGS & 7.8 & $\begin{array}{l}18.81 \mathrm{~N} \\
103.89 \mathrm{~W}\end{array}$ & 5 & $267^{\circ} / 8^{\circ} / 50^{\circ}$ & http://neic.usgs.gov/neis/FM/neic_phac_q.html \\
Harvard & 7.4 & $\begin{array}{l}18.77 \mathrm{~N} \\
103.89 \mathrm{~W}\end{array}$ & 32.6 & $305^{\circ} / 17^{\circ} / 103^{\circ}$ & http://www.seismology.harvard.edu \\
SSN & 7.6 & $\begin{array}{l}18.22 \mathrm{~N} \\
104.60 \mathrm{~W}\end{array}$ & 10 & & http://www.ssn.unam.mx/Colima030121/index.html \\
& & & & \\
IISEE & $(2)$ & $7.62 \mathrm{~N}$ & 20 & $300^{\circ} / 20^{\circ} / 93^{\circ}$ & http://iisee.kenken.go.jp/staff/yagi/eq/colima/colima.html \\
& & $104.12 \mathrm{~W}$ & & & \\
\hline
\end{tabular}

by three different techniques of the ionosphere monitoring: ground-based vertical sounding, vertical sounding from onboard satellites, and GPS TEC technique (Pulinets and Boyarchuk, 2004). In the present study, we have made efforts to analyze the GPS TEC to study the possible association of the ionospheric anomaly with this earthquake event. Data of 5 continuous GPS receivers of INEGI (National Institute of Statistics, Geography and Informatics) network have been analyzed.

Dey and Singh (2003) reported the anomalous variations of the surface latent heat flux (SLHF) for the Colima earthquake. In the present paper we extended the studies of the thermal effects associated with the Colima earthquake, including the analysis of ground-based measurements of the air temperature and relative humidity, as well as the remote sensing data of the MODIS IR sensor from Terra and Aqua satellites.

The temperature increase up to $5^{\circ} \mathrm{C}$ prior to the earthquakes which occurred in Italy, Japan and China was recently observed by Tramutoli et al. (2001) and Tronin et al. (2002). Ouzounov and Freund (2004) have analyzed MODIS data of the Gujarat earthquake in India (M7.7, 26 January 2001) and have found an increase in the land surface temperature and a lowering of the sea surface temperature adjacent to the active tectonic fault. Tramutoli et al. (2005) improved their technique of 2001 and applied it for an analysis of thermal anomalies before the Izmit earthquake in Turkey (M7.4, 19 August 1999).

In this paper, we present the ground measurements of air temperature and relative humidity in the vicinity of the epicenter and also all over Mexico, to study possible irregularities, as well as the satellite measurements of the surface temperature from MODIS, Surface Latent Heat Flux (SLHF) variations and GPS TEC measurements for the set of continuous GPS receivers in Mexico. We also discuss the special technique of GPS data processing which can possibly be used for short-term earthquake prediction. The complementary nature of various anomalies observed on the ground, in the atmosphere and ionosphere are discussed and their joint use show a great potential for early warning of earthquakes.

Geographic positions of epicenters determined by USGS and SSN, INEGI GPS receivers and the meteorological stations of Colima, Manzanillo and Cuernavaca are shown in Fig. 5.

\section{Experimental data}

Numerous types of ground, atmospheric, meteorological, atmospheric and ionospheric data prior to and after the Colima earthquake have been collected. These data sets are discussed in the following sections.

\subsection{Air temperature and relative humidity}

Variations of air temperature and relative humidity in Colima city (19.22 N, 103.7 W) in January 2003 are shown in Fig. 2. The relative humidity has been computed from due point data using the following equations (Sedunov et al., 1997):

$$
\begin{aligned}
& E=6.11 \cdot 10^{(7.5 \cdot T d c /(237.7+T d c))}, \\
& E s=6.11 \cdot 10^{(7.5 \cdot T c /(237.7+T c))},
\end{aligned}
$$

where $T c$ and $T d c$ are the current temperature and current due point temperature, respectively. The relative humidity is calculated as the relation of vapor pressure and saturated vapor pressure

$R H(\%)=100 \cdot(E / E s)$.

This is a standard procedure widely used in meteorology.

Looking at the temperature variations one can clearly see that on 14,15 , and 20 January the daily temperatures are well above the standard deviation and days 14 and 15 are absolute temperature maxima for the whole month. We can conclude that in January 2003 these days can be regarded as anomalous.

At the bottom part of Fig. 2 the variations of relative humidity at Colima are shown. One can see that on 15 January the absolute monthly minimum of the relative humidity 


\section{Colima station}
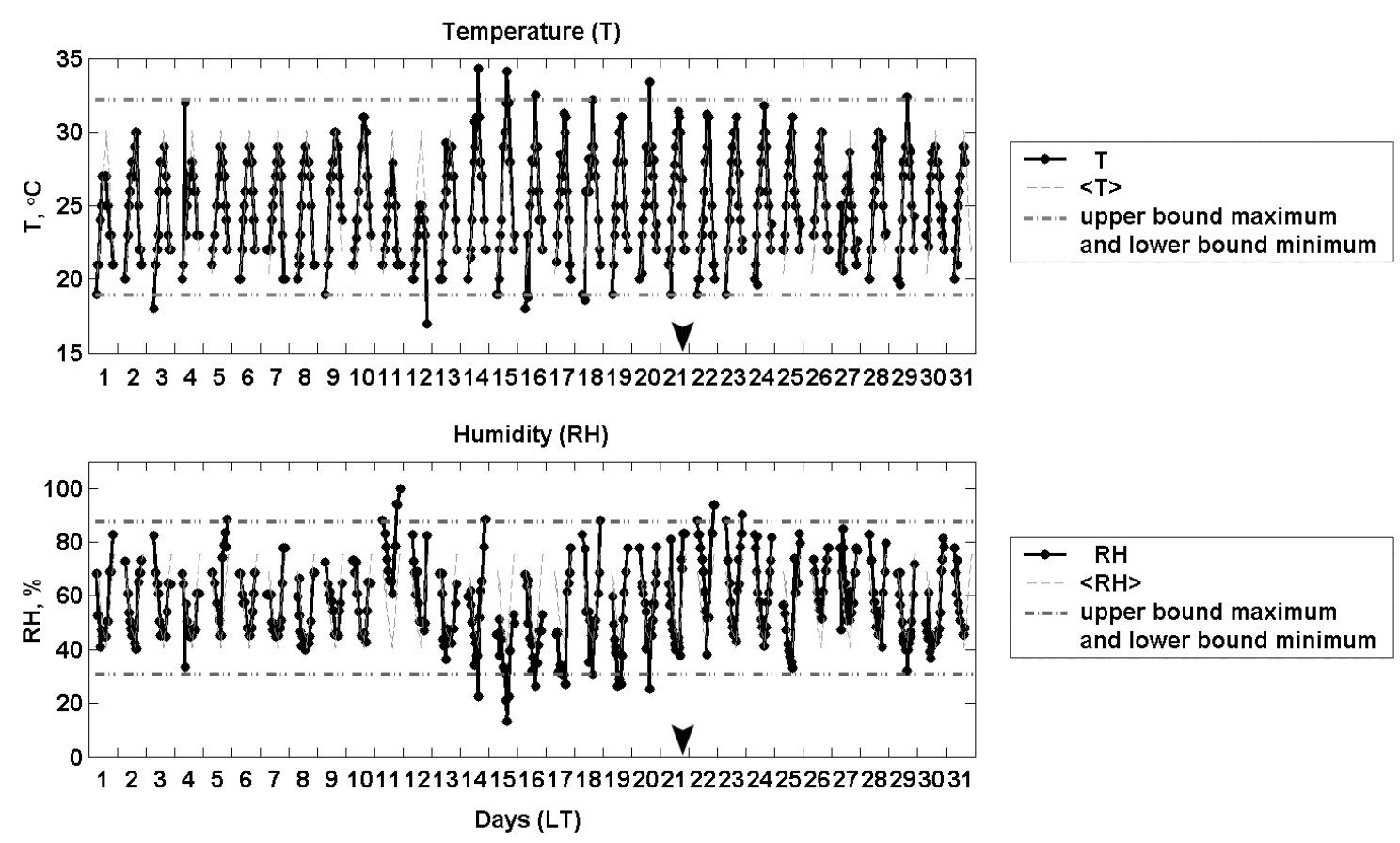

Fig. 2. Upper panel - ground air temperature at Colima station for January 2003, lower panel - relative air humidity at Colima station for January 2003. \$ indicates the earthquake moment.

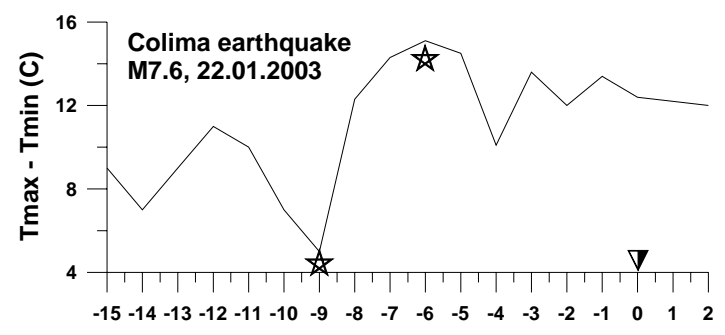

Fig. 3. Daily temperature range at Colima station. Horizontal axis shows the days in relation to the seismic shock. $\$$ indicates the earthquake moment, stars indicate the parameters peculiarities which we interpret as a precursory phenomena.

is observed which is well below the standard deviation, and it drops lower than $20 \%$, which is an extremely low value. Such drops in relative humidity usually are accompanied by an increase in the daily range of the air temperature variations. Pulinets et al. (2006) have demonstrated for several recent important earthquakes that the daily temperature range have a similar pattern for all cases considered. The maximum of the daily temperature range usually is observed one week -5 days before the seismic shock. Daily temperature range variations for Colima station are shown in Fig. 3. Here we can observe the maximum of the daily range 6 days before the seismic shock, which is close in time to the observed air relative humidity minimum. The variations of air temperature and relative humidity at Manznillo (which is at the same distance from epicenter as Colima) are very similar to Colima; due to poor quality we do not show them here.

The observed increase in the temperature, daily temperature range and relative humidity drop is found to be local, since the air temperature and relative humidity at Cuernavaca $(18.92 \mathrm{~N}, 99.25 \mathrm{~W})$, which is at the same latitude as Colima but 5 degrees to the east (Fig. 4), does not show any significant variations prior to the earthquake, except a temperature increase immediately after the earthquake which may be the thermal wave propagating from the epicentral area. We also do not see any relative humidity drop before the earthquake, as it is observed close to the epicenter.

The locality of the thermal effect is also clearly seen in Fig. 5, where the maximum daily temperature distribution over Mexico on 14 January 2003 is shown using data from all country automatic meteorological observatories. Taking into account the altitude relief of Mexico, the temperature measurements were reduced to sea level. The maximum temperature anomaly is found over the epicenter of the impending earthquake. The temperature increase along the active tectonic fault is also found, which is similar to the results of Ouzounov and Freund (2004) and Tramutoli et al. (2005).

We have analyzed multi-year monthly surface temperature data. Figure 6 shows the mean monthly temperature 


\section{Cuernavaca station}

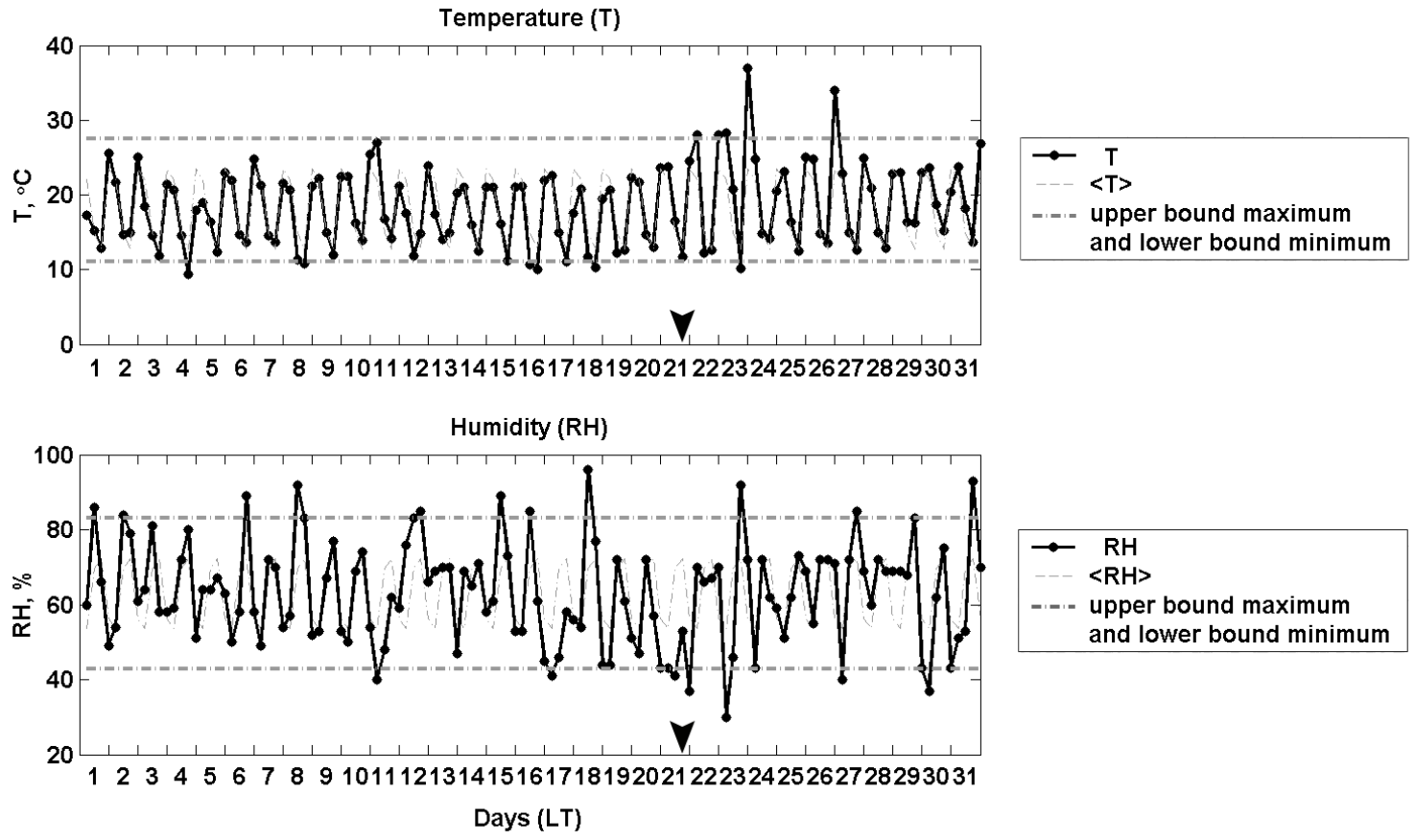

Fig. 4. Upper panel - ground air temperature at Cuernvaca station for January 2003, lower panel - relative humidity at the Cuernvaca station for January 2003. $\$$ indicates the earthquake moment.

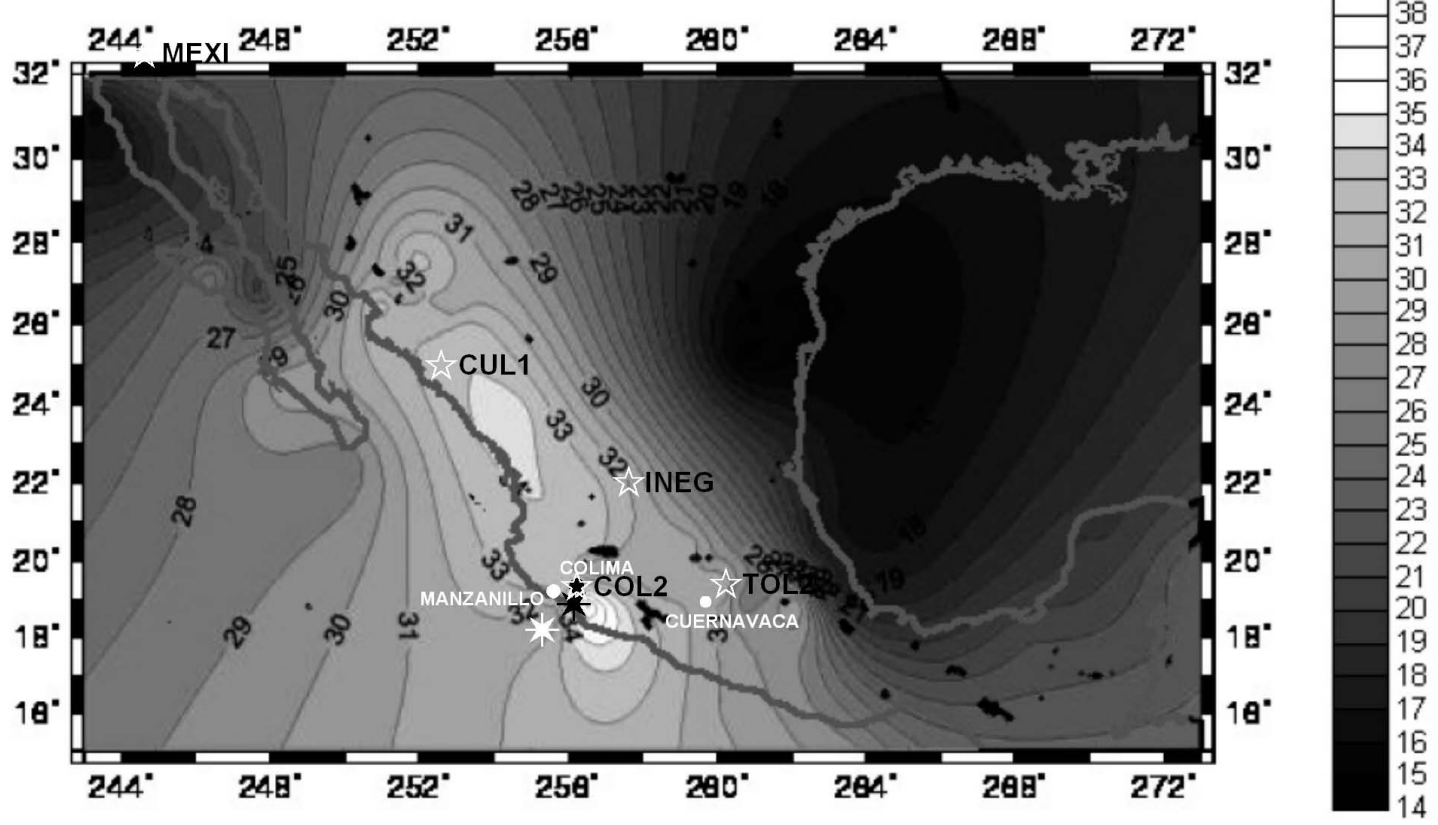

Fig. 5. The map of the surface air temperature at Mexico on 14 January 2003 at 14:10 LT, reduced to the sea surface level. Stars indicate positions of the INEGI GPS receivers; * - epicenter positions determined by NSGS (white) and SSN (black); white dots show positions of meteorological stations at Manzanillo, Colima and Cuernavaca. 


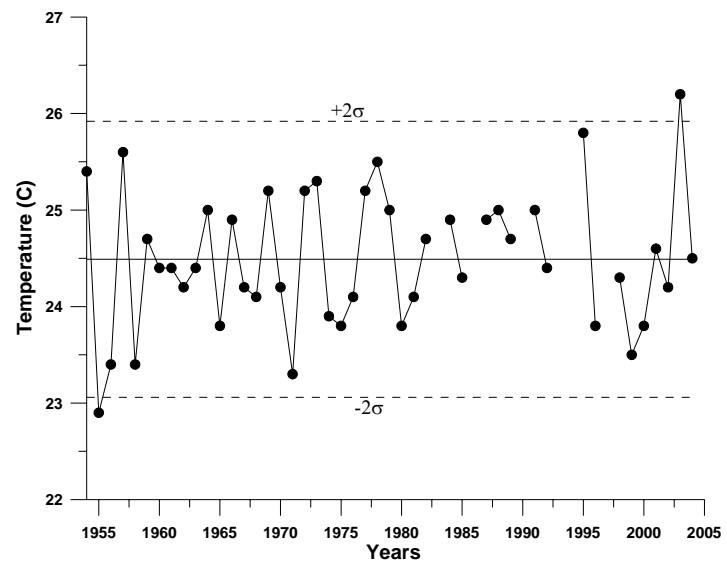

Fig. 6. Mean monthly January temperature at the Manzanillo station for the time interval 1954-2004. Dashed lines - upper and lower bounds of $2 \sigma$ interval.

at Manzanillo for the month of January during the years 1954-2004. In year 2003 (year of the analyzed earthquake) a maximum temperature is observed in the last 50 years. The observed temperature increase is well above the $2 \sigma$ upper bound, which demonstrates its true anomalous character. The anomalous temperature peak on the time intervals of 30-50 years for the mean monthly temperature of the month of the earthquake within the area of preparation of the strong earthquake was reported earlier by Mil'kis (1986) for the major earthquakes in Central Asia.

On the basis of ground temperature and relative humidity variations, one can make the following conclusions:

- The daytime temperature at Colima and Manzanillo is found to be maximum one week prior to the earthquake event of 14 January 2003.

- The range of daily temperature variations is found to be maximum during 14 January 2003.

- The mean monthly temperature at Manzanillo for the month of January is found to be an absolute maximum in 2003 compared to the period during 1954-2004.

- The relative humidity at Colima and Manzanillo for 14-15 January 2003 is found to be an absolute minimum in January 2003.

- The spatial distribution of the air temperature over Mexico one week before the seismic shock shows anomalously high temperatures over the epicenter and along the active tectonic fault.

\subsection{TIR satellite measurements of the surface temperature}

The data of MODIS (MODerate-resolution Imaging Spectroradiometer) on board the Terra and Aqua satellites are analyzed for the period around the time of the Colima earthquake. The satellites have a circular $(705 \mathrm{~km})$ solar synchronized orbit with daytime (near 10:00 LT) and nighttime (near 22:00 LT) passes and register the IR emission in different frequency bands.

Using nighttime and daytime emissions from the Earth's surface, we have analyzed the Land Surface Temperature (LST) data over 90 days by means of the $11-$ to $12-\mu \mathrm{m}$ emissivity ratio covering an area of $50 \times 50 \mathrm{~km}$. To make the thermal anomaly more evident we demonstrate the data as a running average difference between the temperatures measured during the period from 1 December 2002 up to 1 March 2003 and the same time interval of 90 days but from 1 December 2003 up to 1 March 2004. Four curves are presented in Fig. 7: nighttime (Terra satellite, red) and daytime (Aqua satellite blue) temperatures for the square $50 \times 50 \mathrm{~km}$ around the Colima epicenter, nighttime (Terra satellite, green) for the test area $300 \mathrm{~km}$ south of the epicenter, and nighttime (ground air temperature at Colima station, orange).

First of all, one can see the local character of the thermal anomaly. The test area far from the epicenter does not demonstrate any difference between January 2003 and January 2004 (green line) while the sharp increase in the nighttime ground temperature is observed from the beginning of January (red curve). One can also see the sharp increase in the daytime temperature (blue curve) for the middle of January. The true anomalous character of the observed variations demonstrates the fact that the difference between the nighttime temperature in January 2003 and nighttime temperature in January of 2004 reaches 30 deg Celsius.

The ground air nighttime temperature at Colima (orange curve) supports earlier presented results on the mean January temperature (Fig. 6), demonstrating the nighttime difference up to $10^{\circ} \mathrm{C}$ on $15 \mathrm{January}$ between 2003 and 2004, as well as the temporal evolution of the temperature presented in Fig. 3.

We also should mark the propagation direction of the anomaly staring from the ground surface (satellite measurements) and developing 1-2 days later in the boundary layer of the atmosphere (ground air Colima measurements).

\subsection{The variations of the Surface Latent Heat Flux (SLHF)}

Dey and Singh (2003) have found an anomalous surface latent heat flux associated with coastal earthquakes up to 20 days prior to the earthquake. They found that the SLHF anomaly could be a potential precursor in providing early information about an impending coastal earthquake. Cervone et al. (2004) have developed a wavelet analysis approach for identifying maxima peaks associated with an impending earthquake and demonstrating the atmospheric disturbances. They further demonstrated that their methodology works well with the Indian coastal earthquakes (Cervone et al., 2005).

The SHLF data set is represented by a Gaussian grid of 94 lines from the equator to pole, with a regular $1.8 \mathrm{deg}$ longitudinal spacing and is projected onto a $2^{\circ}$ latitude by $2^{\circ}$ 


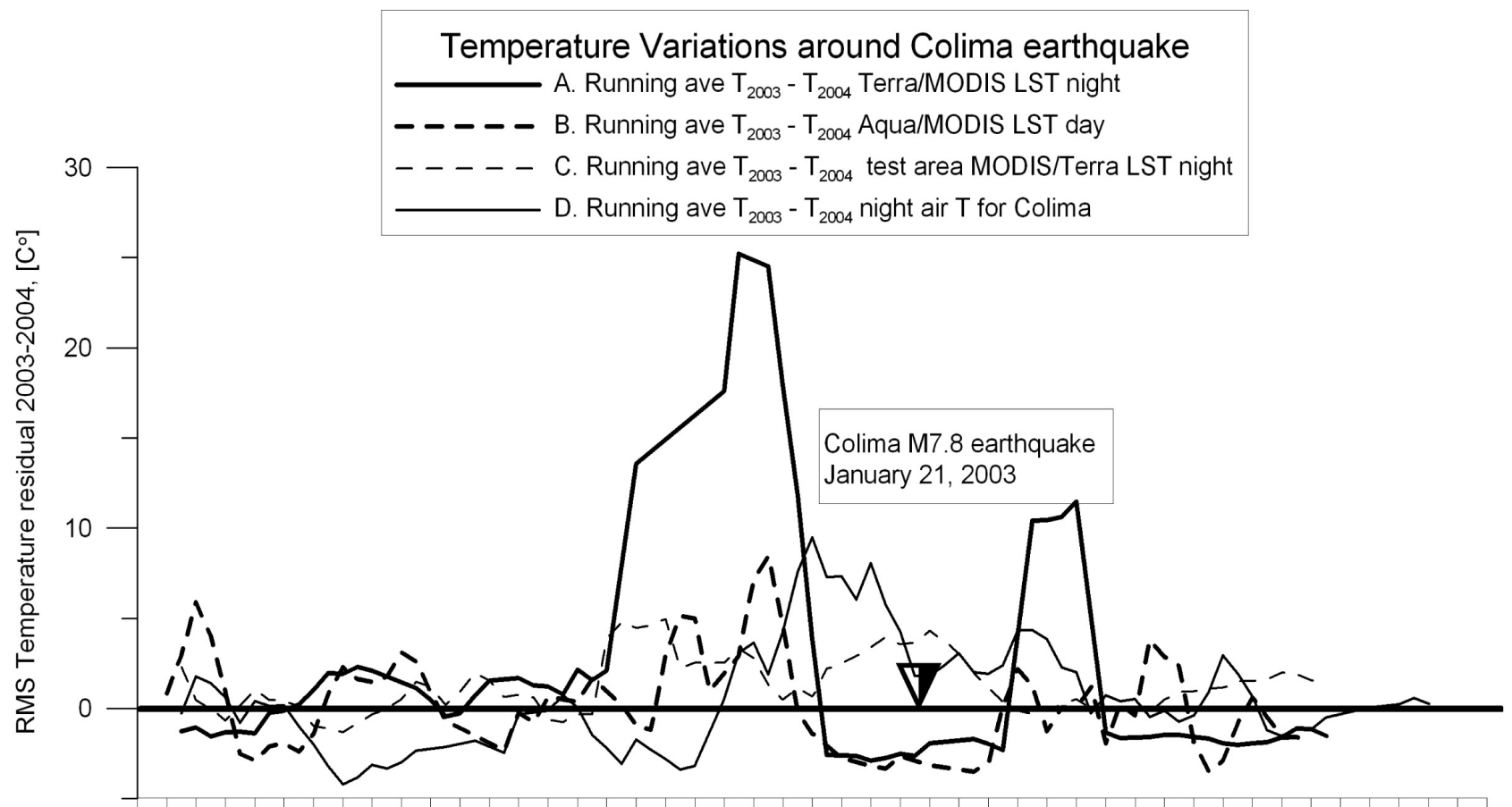

30-Nov 4-Dec 8-Dec 12-Dec 16-Dec 20-Dec 24-Dec 28-Dec 1-Jan 5-Jan 9-Jan 13-Jan 17-Jan 21-Jan 25-Jan 29-Jan 2-Feb 6-Feb 10-Feb 14-Feb 18-Feb 22-Feb 26-Feb 2-Mar

Dec 2002- Feb 2003, [days]

Fig. 7. Joint temperature variations (A, B, and C) satellite, and ground air temperature (D) variations around M7.6 Colima 01.22.2003. Running average of the difference T2003-T2004 of nighttime MODIS/Terra LST (A-bold), daytime MODIS/Aqua LST (B-bold dashed), nighttime MODIS/Terra LST for tested area (300 km south of Colima epicenter) (C-thin dashed), running average of the difference T2003-T2004 of air nighttime temperature ( $\mathrm{D}$ - thin continuous) distribution in the time of the MODIS/Terra satellite local time passing.
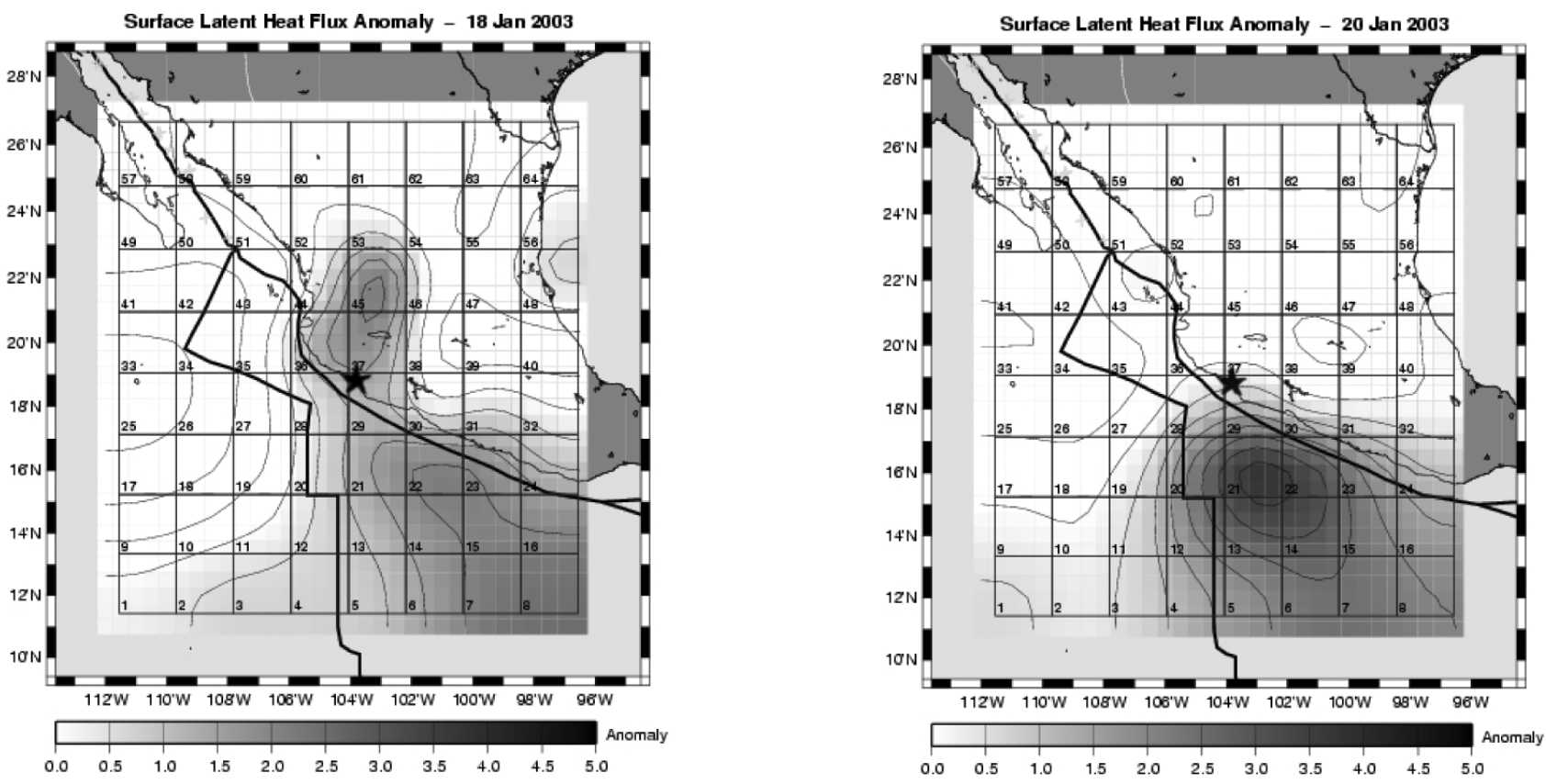

Fig. 8. Left panel - derived Surface Latent Heat Flux (SLHF) on 18 January 2003, right panel - the same for 20 January 2003. Stars indicate the position of the Colima earthquake epicenter. 

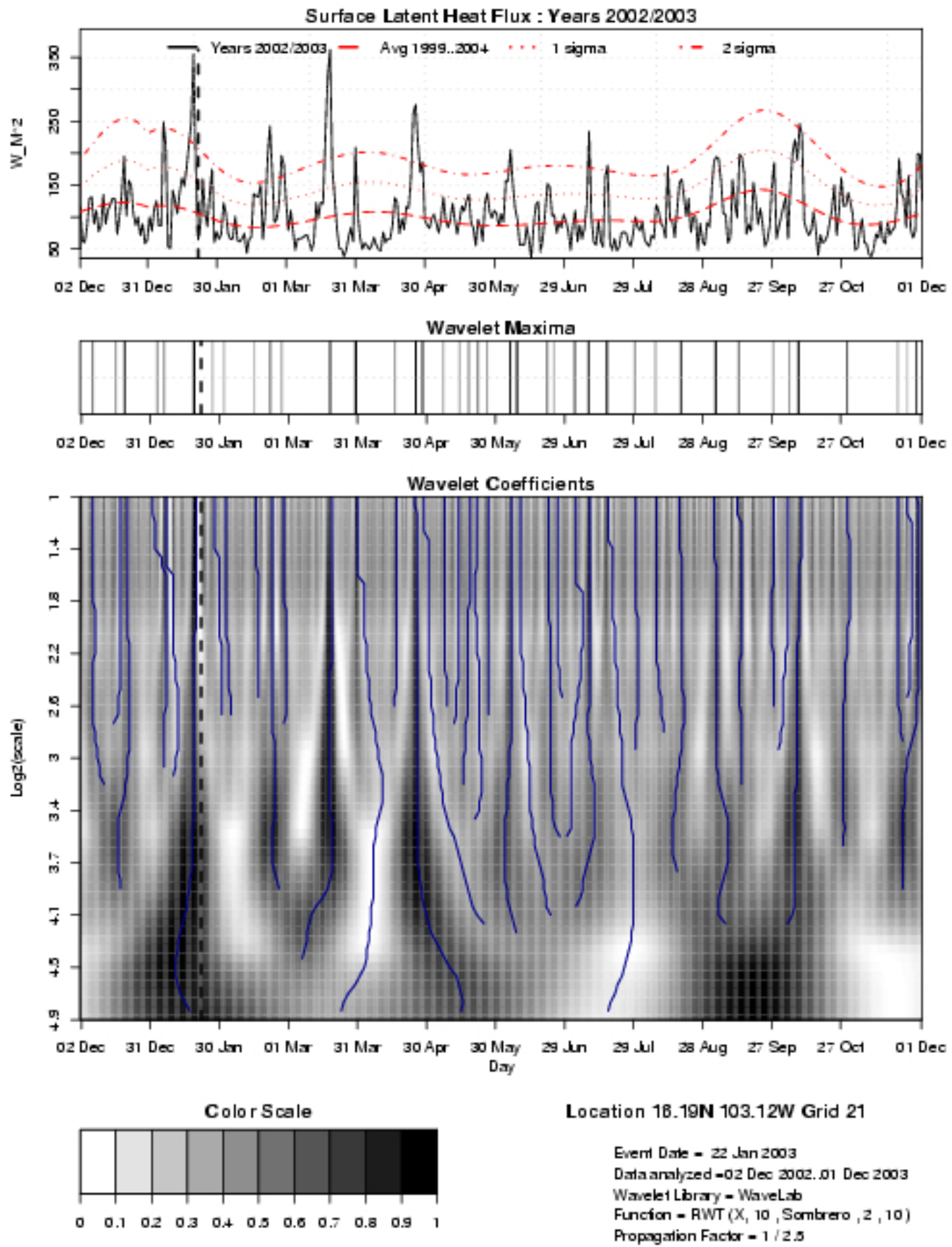

Fig. 9. Wavelet analysis for SLHF data in the vicinity of the Colima earthquake epicenter from 2 December 2002 until 1 December 2003. Top panel - total SLHF, middle panel - wavelet maxima, bottom panel - wavelet coefficients.

longitude irectangular grid which has been downloaded from the Scientific Computing Division of the National Center for Atmospheric Research (NCAR).

Six years of SLHF data for the Colima region were analyzed. Details of SLHF data sources and processing are given by Cervone et al. (2004). Wavelet maxima curves have been used to identify singularities in the data, or times of sharp changes in the first derivative of a function (Cervone et al., 2004). This technique is advantageous for identifying peaks in a time series, while filtering out high frequency noise and low frequency seasonal and interannual effects. The data are normalized by subtracting from the 2004 time series the 


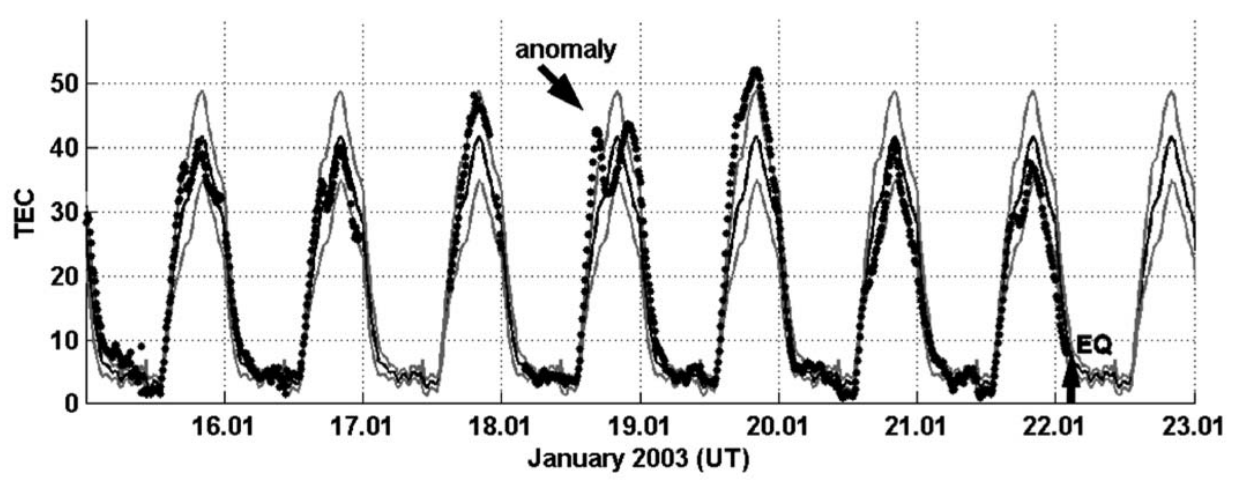

Fig. 10. Vertical TEC variations (points) in comparison with the monthly mean (black line). Grey lines-upper and lower bounds calculated as monthly mean $\pm \sigma$.

5-year (1998-2002) average, and dividing by the standard deviation. The normalization is done to identify anomalies or times where peaks are considerably above the normal fluctuation of the data.

Prominent anomalies higher than $3 \sigma$ are found within the time interval between 3 and 5 days prior to the earthquake event. Figures $8 \mathrm{a}$ and $\mathrm{b}$ show, respectively, the SLHF anomalies for 18 and 20 January 2003. The strongest anomalies are detected at and around the epicentral area, mainly confined within $400 \mathrm{~km}$ of the epicenter.

Figure 9 shows the wavelet transformation and the resulting maxima curves performed for the grid where the highest anomaly is found, immediately south of the epicenter, over the ocean. Several peaks are identified throughout the year, seven of which are above the $2 \sigma$ significance line. The highest peak occurs three days prior to the earthquake event, which is likely to be associated with the earthquake preparatory process. Several other prominent and statistically significant peaks are observed at the same time or within a 1-day delay over other grids lying on the continental boundary. Such anomalies exhibit a rigorous geometrical continuity in both space and time which can help to discriminate between signals associated with earthquakes from signals due to other phenomena (Cervone, 2004). The other peaks which show above $2 \sigma$ significance lines are likely to be associated with atmospheric perturbations.

\subsection{GPS TEC data analysis}

To detect ionospheric variations associated with the Colima earthquake, the data of 5 INEGI permanent GPS receivers are used (Table 2). For every station the time series of the vertical TEC (VTEC) and monthly mean $(M)$ are computed. The VTEC is computed using a technique described in Ciraolo and Spalla (1997), and then the percentage deviation: $\triangle T E C(\%)=100 \cdot(V T E C-M) / M$ for January 2003 is computed. For better temporal resolution in the graph the time series for Colima receiver (closest to the epicenter) is
Table 2. Coordinates of the INEGI GPS stations.

\begin{tabular}{ccc}
\hline Station & Latitude $(\mathrm{N})$ & Longitude $(\mathrm{W})$ \\
\hline COL2 & 19.244 & 103.702 \\
CUL1 & 24.799 & 107.384 \\
INEG & 21.856 & 102.284 \\
MEXI & 32.633 & 115.476 \\
TOL2 & 19.293 & 99.643 \\
\hline
\end{tabular}

presented in Fig. 10 for only several days in January around the time of the Colima earthquake. The dots indicate the current measurements, the back continues line - the monthly median, and the grey lines show the $\mathrm{M}-\sigma$ and $M+\sigma$ lower and upper bounds. One can see that the VTEC exceeds the upper bound on 18 and 19 January, which can serve as an indicator of anomalous variations. To check if the observed variations are really local and are connected with the earthquake preparation process, a map of VTEC spatial distribution was created using the data of 5 receivers from Table 2.

The time of the peak on 18 January (10:10 LT) was selected for the map construction. Using the spatial interpolation with the Kriging technique (Oliver and Webster, 1990), the map of the TEC deviation from the monthly mean was build and is presented in Fig. 11. It clearly shows the local character of the observed anomaly and its close proximity to the impending earthquake epicenter. This anomalous deviation can be interpreted as a short-term precursor of the Colima earthquake, appearing more than three days before the earthquake ( $82 \mathrm{~h}$ before). The abnormality of the 10:10 LT peak on 18 January is determined not only by formal deviation from the monthly mean but from the morphology of the equatorial anomaly behavior in local time, which is discussed in Pulinets et al. (2005).

Another technique is applied to the GPS TEC data where the locality of the ionospheric precursor is used (Pulinets et 


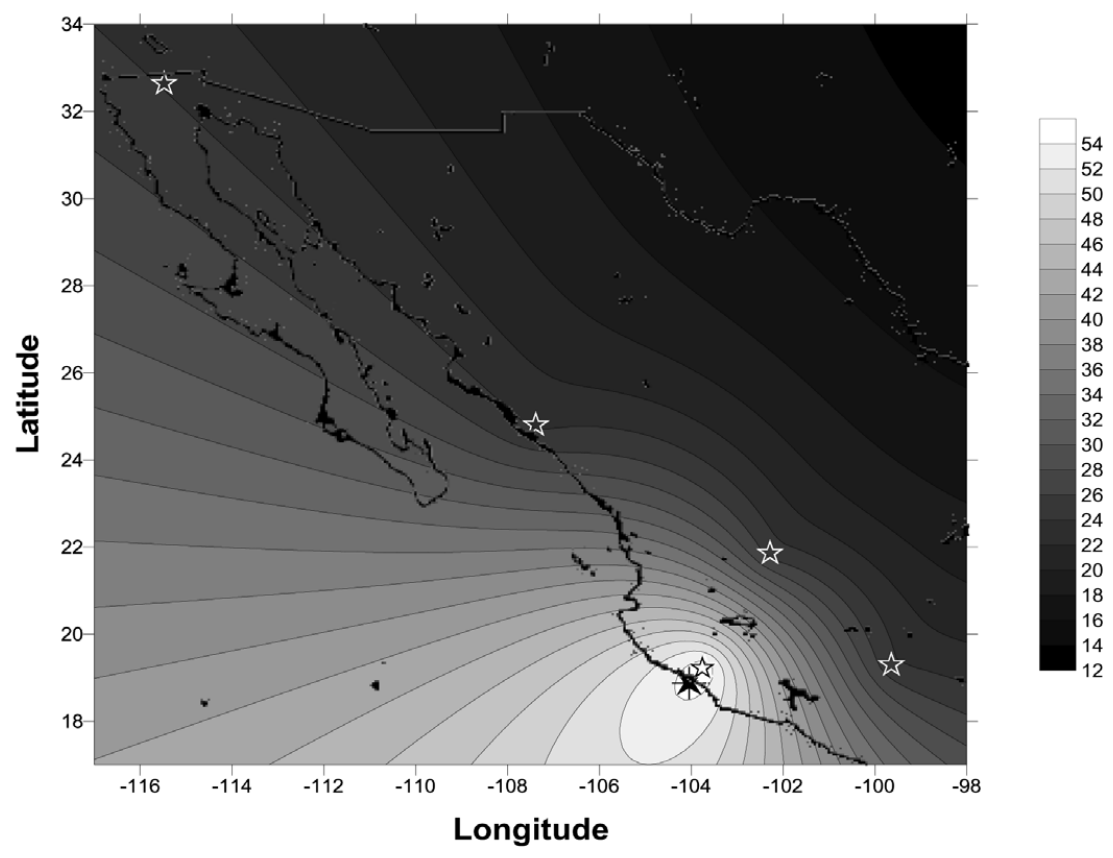

Fig. 11. Spatial distribution of $\triangle$ TEC obtained from the data of the INEGI GPS receivers network for 10:10 LT on 18 January 2003. Stars indicate positions of GPS receivers.

al., 2004). It implies that around the time of the seismic shock the character of the ionosphere variability is different in the ionosphere over the epicenter than over the remote station, which leads to the drop in the cross-correlation coefficient between them. This technique is checked for many earthquakes, including the Colima earthquake, and for the last earthquake the results of the calculation are presented in Fig. 12.

The COL2 receiver, closest to the epicenter, could be used as a "sensor" station but due to the power break after the earthquakes it stopped its operation for one day. In the absence of near station data, we have used the Toluca receiver, TOL2, as a "sensor". Figure 12 shows the crosscorrelation coefficients for the pairs (from top to bottom) Toluca-Culiacan, Toluca-Aguascalients and AguascalientsCuliacan. One can see the drop in the correlation coefficient 5-day earthquake event in the two upper panels (Fig. 12) and practically no drops in the lower one. This means that the ionosphere over Toluca, which is closer to the epicenter, is more variable several days prior to the earthquake event (Pulinets et al., 2005). The maximum of the local variability is reached between 17 and 18 January. The ionospheric variations over Aguascalientes and Culiacan are almost synchronous, which gives the high value of the daily cross-correlation coefficient (bottom panel of Fig. 12). So the locality of the ionospheric variations associated with the earthquake preparation process is used for their identification.

\section{Physical explanation of the observed thermal and ionospheric anomalies}

3.1 Natural radioactivity - the source of the variations in atmosphere electricity and latent heat

The changes in the near ground air electricity as a result of natural radioactivity were studied as early as in 60-th (Bricard, 1965). It happens due to air ionization by radon (and its progeny products) emanating from the Earth's crust as a primary process, and due to changes in the air conductivity through the formation of large ion clusters. Formation of such clusters was demonstrated by Bricard et al. (1968) under laboratory conditions by injecting of thoron (one of the radon isotopes) into pure air. The natural ionization is inherent to our environment, and natural radioactivity plays an important role in the formation of atmospheric aerosols (Wilding and Harrison, 2005). Formation of aerosols happens due to water molecule attachment to newly formed ions. This process simultaneously changes the parameters of atmospheric electricity, as well as the air temperature and relative humidity (Toutain and Baubron, 1998; Prasad et al., 2005). A detailed description of all plasmachemical processes resulting from ionization can be find in Boyarchuk et al. (2005). We only describe briefly the main stages of this process.

Under the action of radon ionization a large amount of $\mathrm{O}_{2}^{+}$ ions is formed in atmosphere in the initial stage, both as a result of direct ionization, and as a result of the charge exchange between an initial ion $\mathrm{N}_{2}^{+}$and electrons, which fast 
adhere to atoms of oxygen, since the oxygen has a significant energy of affinity to electrons, forming the negative ions $\mathrm{O}^{-}$and $\mathrm{O}_{2}^{-}$(Pulinets and Boyarchuk, 2004). As a result of fast ion-molecular reactions during an interval of the order of $10^{-7} \mathrm{~s}$ the main elementary tropospheric ions will be formed: $\mathrm{O}^{-}, \mathrm{O}_{2}^{-}, \mathrm{NO}_{2}^{-}, \mathrm{NO}_{2}^{-} \mathrm{NO}_{3}^{-}, \mathrm{CO}_{3}^{-}$and $\mathrm{O}_{2}^{+}, \mathrm{NO}^{+}, \mathrm{H}_{3} \mathrm{O}^{+}$. The concentration of electrons is so insignificant that they can be neglected. The large amount of water vapor molecules contained in the troposphere $\left(\sim 10^{17} \mathrm{~cm}^{-3}\right)$, having a noticeable dipole moment $p=1.87 \mathrm{D}$, leads to hydration of elementary ions and the formation of ion complexes of a type $\mathrm{NO}_{2}^{-} \cdot\left(\mathrm{H}_{2} \mathrm{O}\right)_{\mathrm{n}}$ and $\mathrm{NO}_{3}^{-} \cdot\left(\mathrm{H}_{2} \mathrm{O}\right)_{\mathrm{n}}, \mathrm{NO}_{3}^{-} \cdot\left(\mathrm{HNO}_{3}\right)_{\mathrm{n}}\left(\mathrm{H}_{2} \mathrm{O}\right)_{\mathrm{m}}$ and $\mathrm{O}_{2}^{+} \cdot\left(\mathrm{H}_{2} \mathrm{O}\right), \mathrm{NO}^{+} \cdot\left(\mathrm{H}_{2} \mathrm{O}\right)_{\mathrm{n}}, \mathrm{H}^{+} \cdot\left(\mathrm{H}_{2} \mathrm{O}\right)_{\mathrm{m}}$ and $\mathrm{H}_{3} \mathrm{O}^{+} \cdot\left(\mathrm{H}_{2} \mathrm{O}\right)_{\mathrm{n}}$ which happens rather fast. We should mention here that the hydration process does not depend on the relative air humidity; it takes place under any conditions. It is estimated that the ion concentration in the area of the earthquake preparation can reach $10^{5}-10^{6} \mathrm{~cm}^{-3}$, which essentially changes the electric properties of the near ground layer of the atmosphere. The consequence of this process is the change in the air conductivity which creates the possibility of the anomalous electric field generation. As a result of the local changes in the atmosphere electricity the local changes of the electron concentration variability are induced in the ionosphere, which can be registered by different techniques of the ionosphere monitoring.

The chemical changes in the near ground layer of the atmosphere have one more important consequence: the attachment of the water molecules to the newly formed ions. In the sense of an energy state of the water molecule, the process of attachment to an ion is equivalent to the process of water vapor condensation. It is well known that the condensation process is accompanied by a release of the latent heat of evaporation. The effectiveness of this process is $\sim 800-900 \mathrm{cal} / \mathrm{g}$. But the difference from the pure water molecules' condensation is that the attachment process does not depend on the air humidity: it takes place under any level of humidity and doesn't need the condition of saturation. The final result, which is expressed in terms of changes in the relative humidity and the heat released, will depend on the ionization effectiveness and on the number of water molecules attached to the newly formed ions. Theoretical calculations (Boyarchuk et al., 2005) and experimental measurements (Wilding and Harrison, 2005) show that more than 100 water molecules can be attached to one ion.

In the thermal radiative balance of the atmosphere (total radiative heat budget is $\sim 185 \mathrm{~W} / \mathrm{m}^{2}$ ), the latent heat of the water evaporation is very significant $\left(\sim 88 \mathrm{~W} / \mathrm{m}^{2}\right)$. It means that by changing the latent heat balance the air temperature can be significantly changed. During the occurence of water condensation on ions, the large number of the water molecules can be attached to the ion. This means that the ion cluster grows to some critical mass $m_{\max }$. The heat deposit
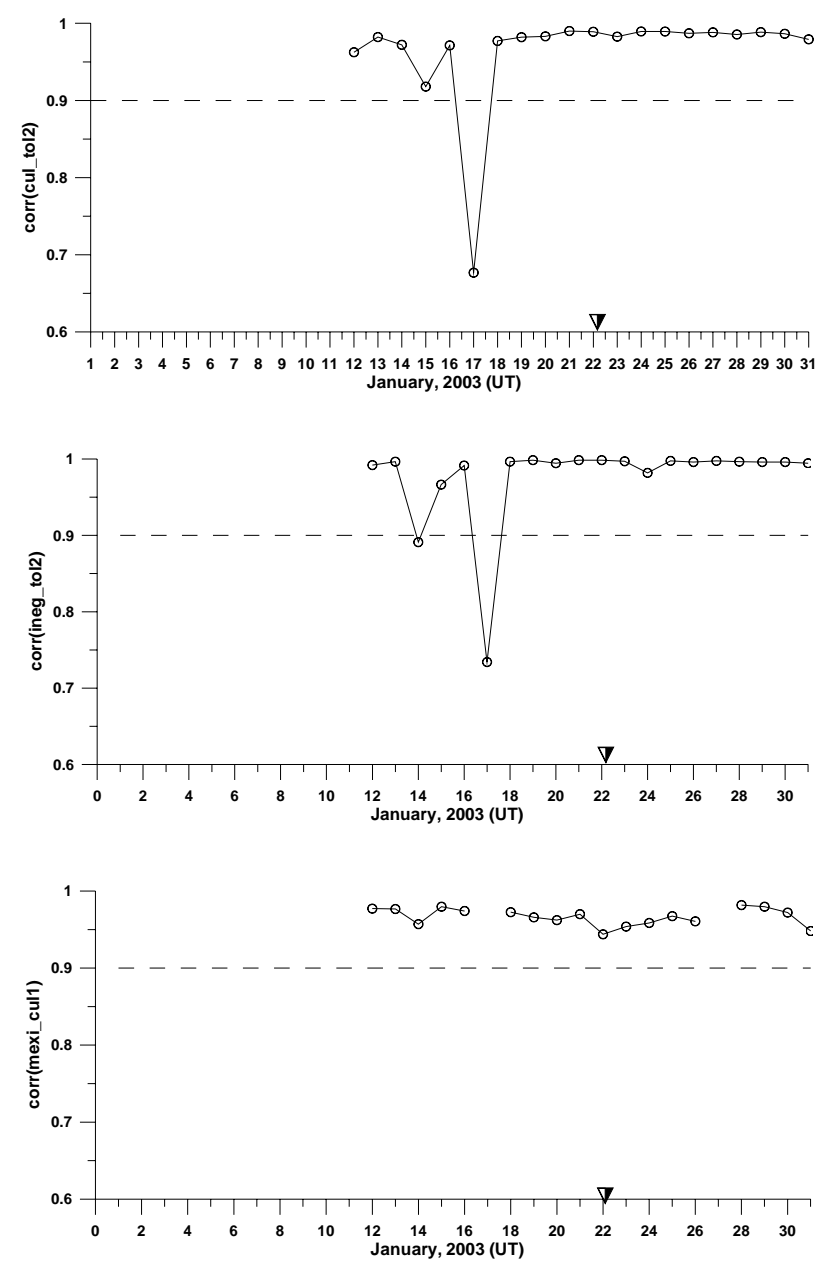

Fig. 12. Daily cross correlation coefficients calculated for the pairs of GPS receivers. From top to bottom Culiacan - Toluca, Aguascalients - Toluca, Culiacan - Aguascalientes.

$w$ is equal to:

$w=m_{\max } U_{0}$,

where $U_{0}$ is the specific heat of evaporation. If the ionization source produces the ions with the velocity $d N / d t$, the heat deposited into the atmosphere can be expressed as (Pokhmelnykh, 2003):

$P_{a}=w \cdot d N / d t$.

Each $\alpha$-particle emitted by ${ }^{222} \mathrm{Rn}$, with the average energy of $\mathrm{E}_{\alpha}=6 \mathrm{MeV}$, can produce theoretically about $2.73 \cdot 10^{5}$ electron-ion pairs. The radon concentration in the air can vary in different geophysical conditions. One can find correspondent values for Mexico in Segovia et al. (2005, Table 1). Even under normal conditions we can expect the radon concentration on the ground level to be $100-300 \mathrm{~Bq} / \mathrm{m}^{3}$, which gives the rate of ionization of $30-90 \mathrm{~cm}^{-3} \mathrm{~s}^{-1}$. We will use these estimates for calculations of the air humidity changes under the action of radon ionization. 


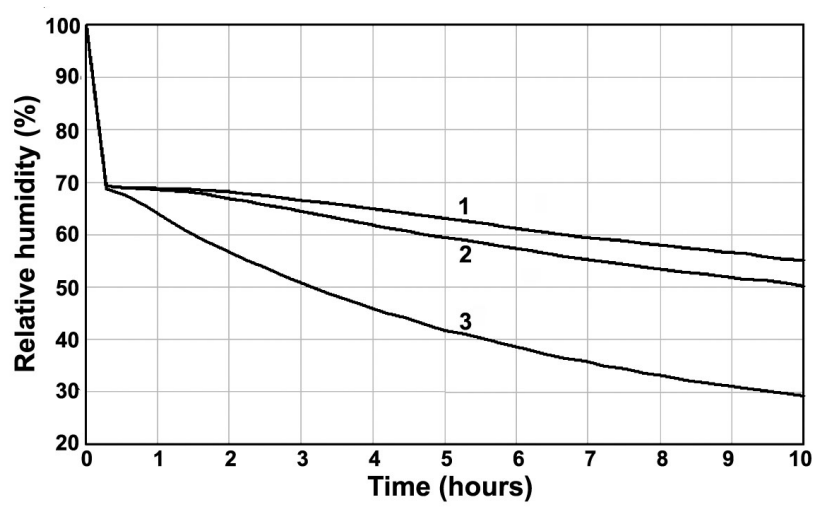

Fig. 13. Model calculations of relative humidity changes under ionization impact for the three values of the chemical potential correction $\Delta U=0.019$ (curve 1); 0.022 (curve 2) and $0.03 \mathrm{eV}$ (curve 3).

The final consideration asks whether the changes in the atmospheric electricity are under the action of natural ionization. Roble and Tzur (1986) show an increase in the atmospheric electric field under the presence of aerosols. Prasad et al. (2005) demonstrate the changes in the air conductivity under the action of radon ionization. Pulinets et al. (2000) make the model calculations of the atmospheric electric field changes in the presence of the flux of aerosols, showing an essential increase in the electric field. Under excess of the positive ions the model calculations show the possibility of the reversed direction of the atmospheric electric field in comparison with the natural direction.

Summarizing the effects of natural ionization on the boundary layer of the atmosphere we can expect the changes in the relative air humidity (diminishing), air temperature (increase), and atmospheric electric field (increase or reversed).

\subsection{Atmosphere modification before earthquakes}

Toutain and Baubron (1998) in their comprehensive review report the increase of radon concentration up to $1200 \%$ (see Table 1 in the cited paper). Inan et al. (2005) demonstrates the radon concentration increase up to 3 times in comparison with the background leveling Turkey. This value seems reasonable for our estimations. It means that we can expect by using the Mexican data of radon measurements a radon concentration on the ground level of $300-400 \mathrm{~Bq} / \mathrm{m}^{3}$, which is equivalent to the ionization rate of $90-100 \mathrm{~cm}^{-3} \mathrm{~s}^{-1}$.

It should be noted that the ionization itself does not produce energy for the air temperature rise; it only produces the ions as the centers of water condensation. The energy is already stored in water vapor and ionization only helps to release the stored heat. Taking into account that the ionization anomalies take place within the large areas of the earthquake preparation zone, the effects of the meteorological scale can be caused by a comparatively small increase in the air ionization. Mil'kis (1986) demonstrates the thermal anomalies before a strong earthquake in Central Asia within the areas of the order of $400000 \mathrm{~km}^{2}$. Ouzounov and Freund (2004), using IR satellite images, demonstrate the dynamics of the temperature increase over the huge system of active tectonic faults before the Gujarat (M7.8) earthquake of 26 January 2001.

We should emphasise that the water molecules' attachment to ions is not equivalent to the pure water condensation. It has a different velocity of the ionization/evaporation from that of pure water, due to the changes in the chemical potential. Evaporation and condensation are the phase transitions of the first order. The phase transition happens under chemical potential equality. For the one-component system the chemical potential is equal to the thermodynamic potential related to the one particle. This means that the latent evaporation heat $U$ is equal to the Gibbs chemical potential of the molecule in the water drop. At the same time the evaporation latent heat is equal to the work function, which, in turn, is equal to the energy of the dipole-dipole interaction at the distance $r=2.46 \AA$, which is a water molecule radius. Under the action of radiation the newly formed ions enter the chain of plasmachemical reactions, leading to the complex ion cluster formation. These clusters become the centers of condensation but with other work function and other chemical potential. The changes in the chemical potential were taken into account in calculations of relative humidity:

$$
\begin{aligned}
H(t) & =\frac{\exp (-U(t) / k \cdot T)}{\exp \left(-U_{0} / k \cdot T\right)}=\exp \left(\frac{U_{0}-U(t)}{k \cdot T}\right) \\
& =\exp \left(-\frac{0.032 \cdot \Delta U \cdot \cos ^{2} t}{(k \cdot T)^{2}}\right) .
\end{aligned}
$$

$U(t)=U_{0}+\Delta \mathrm{U} \cdot \cos ^{2} t, \Delta U-$ is the chemical potential correction as a result of external impact.

The detailed calculations of the water vapor number in the air were made using the complete kinetic model of the air by taking into account all the possible components shown in Table 3. For calculations of the chemical potential (and correspondent relative humidity) variations, 3 levels of the ionization rate were used: $4.5,9$ and $90 \mathrm{~cm}^{-3} \mathrm{~s}^{-1}$. They give the chemical potential changes $\Delta U=0.019 ; 0.022$ and $0.03 \mathrm{eV}$, respectively. The results of the model calculation of the relative humidity changes are presented in Fig. 13. One can see that for the maximum ionization rate the relative humidity can change from $100 \%$ up to less than $30 \%$ during $10 \mathrm{~h}$. Taking into account that the radon semi-decay period is 3.8 days, the single intensive radon release is sufficient to produce significant changes in the relative air humidity.

The selected levels of the ionization rate look quite reasonable and give the values of the relative humidity measured at the Colima station (Fig. 14). The blue line represents the reversed value of the experimentally measured relative humidity at the Colima station, and the red line is the reversed 
Table 3. Neutral and ionized components used in calculations of the relative air humidity changes.

\begin{tabular}{|c|c|}
\hline Type of molecules and ions & Chemical formulas \\
\hline Neutral atoms and molecules & $\begin{array}{l}\mathrm{NO}, \mathrm{NO}_{2}, \mathrm{NO}_{3}, \mathrm{~N}_{2} \mathrm{O}_{5}, \mathrm{~N}_{2} \mathrm{O}, \mathrm{O}, \mathrm{N}, \mathrm{H}, \mathrm{HO}_{2}, \mathrm{H}_{2}, \mathrm{OH}, \mathrm{H}_{2} \mathrm{O}_{2}, \mathrm{HNO}, \mathrm{HNO}_{2}, \mathrm{HNO}_{3}, \mathrm{HNO}_{4}, \mathrm{C}, \\
\mathrm{CN}\end{array}$ \\
\hline Excited atoms and molecules & $\mathrm{O}_{2}^{*}\left({ }^{1}\right), \mathrm{O}^{*}\left({ }^{1} \mathrm{D}\right), \mathrm{O}^{*}\left({ }^{1} \mathrm{~S}\right), \mathrm{N}_{2}^{*}(\mathrm{~A}), \mathrm{N}^{*}\left({ }^{2} \mathrm{D}\right)$ \\
\hline Positive ions & $\begin{array}{l}\mathrm{N}^{+}, \mathrm{N}_{2}^{+}, \mathrm{N}_{3}^{+}, \mathrm{N}_{4}^{+}, \mathrm{O}^{+}, \mathrm{O}_{2}^{+}, \mathrm{O}_{4}^{+}, \mathrm{O}_{6}^{+}, \mathrm{O}_{8}^{+}, \mathrm{H}^{+}, \mathrm{H}_{2}^{+}, \mathrm{H}_{3}^{+}, \mathrm{NO}^{+}, \mathrm{NO}_{2}^{+}, \mathrm{NO}_{3}^{+}, \mathrm{N}_{3} \mathrm{O}^{+}, \mathrm{N}_{2} \mathrm{O}_{2}^{+}, \\
\mathrm{N}_{2} \mathrm{O}_{3}^{+}, \mathrm{H}_{2} \mathrm{O}^{+}, \mathrm{OH}^{+}, \mathrm{H}^{+} \mathrm{O}_{2}, \mathrm{H}^{+}\left(\mathrm{H}_{2} \mathrm{O}\right), \mathrm{O}_{2}^{+}\left(\mathrm{H}_{2} \mathrm{O}\right), \mathrm{H}_{2} \mathrm{O}^{+}\left(\mathrm{H}_{2} \mathrm{O}\right), \mathrm{O}_{2}^{+}\left(\mathrm{H}_{2} \mathrm{O}\right)_{2}, \mathrm{H}^{+}\left(\mathrm{H}_{2} \mathrm{O}\right)_{2}, \\
\mathrm{H}^{+}\left(\mathrm{H}_{2} \mathrm{O}\right)_{3}, \mathrm{H}^{+}\left(\mathrm{H}_{2} \mathrm{O}\right)_{4}, \mathrm{H}^{+}\left(\mathrm{H}_{2} \mathrm{O}\right)_{5}, \mathrm{H}^{+}\left(\mathrm{H}_{2} \mathrm{O}\right)_{6}, \mathrm{H}^{+}\left(\mathrm{H}_{2} \mathrm{O}\right)_{7}, \mathrm{H}^{+}\left(\mathrm{H}_{2} \mathrm{O}\right)_{8}, \mathrm{H}^{+}\left(\mathrm{H}_{2} \mathrm{O}\right) \mathrm{O}_{2}, \mathrm{~N}_{2} \mathrm{H}^{+}, \\
\mathrm{H}^{+}\left(\mathrm{N}_{2} \mathrm{O}\right), \mathrm{N}^{+}\left(\mathrm{H}_{2} \mathrm{O}\right), \mathrm{NO}^{+}\left(\mathrm{H}_{2} \mathrm{O}\right), \mathrm{NO}_{2}^{+}\left(\mathrm{H}_{2} \mathrm{O}\right), \mathrm{H}^{+}\left(\mathrm{H}_{2} \mathrm{O}\right) \mathrm{N}_{2}, \mathrm{NO}^{+}\left(\mathrm{H}_{2} \mathrm{O}\right)_{2}, \mathrm{NO}_{2}^{+}\left(\mathrm{H}_{2} \mathrm{O}\right)_{2}, \\
\mathrm{NO}^{+}\left(\mathrm{H}_{2} \mathrm{O}\right)_{3}, \mathrm{NO}^{+}\left(\mathrm{H}_{2} \mathrm{O}\right) \mathrm{N}_{2}, \mathrm{NO}^{+}\left(\mathrm{H}_{2} \mathrm{O}\right)_{2} \mathrm{~N}_{2}, \mathrm{C}^{+}, \mathrm{CO}^{+}, \mathrm{CO}_{2}^{+}, \mathrm{O}^{+}\left(\mathrm{CO}_{2}\right), \mathrm{O}_{2}^{+}\left(\mathrm{CO}_{2}\right), \\
\mathrm{CO}^{+}(\mathrm{CO}), \mathrm{CO}^{+}\left(\mathrm{CO}_{2}\right), \mathrm{CO}_{2}^{+}\left(\mathrm{CO}_{2}\right), \mathrm{O}_{2}^{+}\left(\mathrm{CO}_{2}\right)_{2}, \mathrm{CO}^{+}\left(\mathrm{CO}_{2}\right) \mathrm{CO}, \mathrm{H}^{+}(\mathrm{CO}), \mathrm{H}^{+}\left(\mathrm{CO}_{2}\right), \\
\mathrm{CO}_{2}^{+}\left(\mathrm{H}_{2} \mathrm{O}\right), \mathrm{NO}^{+}\left(\mathrm{CO}_{2}\right), \mathrm{NO}^{+}\left(\mathrm{H}_{2} \mathrm{O}\right) \mathrm{CO}_{2}, \mathrm{NO}^{+}\left(\mathrm{H}_{2} \mathrm{O}\right)_{2} \mathrm{CO}_{2}, \mathrm{CO}^{+}\left(\mathrm{H}_{2} \mathrm{O}\right), \mathrm{H}^{+}(\mathrm{CO})_{2}\end{array}$ \\
\hline Negative ions & $\begin{array}{l}\mathrm{O}^{-}, \mathrm{O}_{2}^{-}, \mathrm{O}_{3}^{-}, \mathrm{NO}_{2}^{-}, \mathrm{O}^{-}\left(\mathrm{NO}_{2}\right), \mathrm{O}_{2}^{-}\left(\mathrm{H}_{2} \mathrm{O}\right), \mathrm{O}_{3}^{-}\left(\mathrm{H}_{2} \mathrm{O}\right), \mathrm{O}_{2}^{-}\left(\mathrm{H}_{2} \mathrm{O}\right)_{2}, \mathrm{NO}_{3}^{-}\left(\mathrm{HNO}_{3}\right), \mathrm{NO}_{2}^{-}\left(\mathrm{H}_{2} \mathrm{O}\right) \text {, } \\
\mathrm{NO}_{3}^{-}\left(\mathrm{H}_{2} \mathrm{O}\right), \mathrm{NO}_{3}^{-}\left(\mathrm{H}_{2} \mathrm{O}\right) \mathrm{HNO}_{3}, \mathrm{NO}_{3}^{-}\left(\mathrm{HNO}_{3}\right)_{2}, \mathrm{O}^{-}\left(\mathrm{CO}_{2}\right), \mathrm{O}_{2}^{-}\left(\mathrm{CO}_{2}\right), \mathrm{O}^{-}\left(\mathrm{CO}_{2}\right) \mathrm{H}_{2} \mathrm{O} \text { and } \\
\text { electrons }\end{array}$ \\
\hline
\end{tabular}

value of the calculated relative humidity. From top to bottom, $\Delta U=0.019 ; 0.022$ and $0.03 \mathrm{eV}$. One can see that different values of $\Delta U$ correspond to different values of the related humidity measured experimentally.

\subsection{Ionosphere modification before earthquakes}

Toutain and Baubron (1998) after an analysis of close to 170 publications on the geochemical precursors of earthquakes have demonstrated that the spatial distribution of radon anomalies follows the Dobrovolsky et al. (1979) dependence on the earthquake magnitude: $\lg R=0.43 \mathrm{M}$, where $R$ is the radius where the radon anomalies are observed, and $M$ is the earthquake magnitude. This means that for the M7.6 earthquake the radius $R$ will be more than $1800 \mathrm{~km}$. As it was shown earlier, the radon anomalies will produce the anomalies of the atmospheric electric field. As it was shown by $\mathrm{Pu}-$ linets et al. (2000) and Pulinets and Boyarchuk (2004) such a large-scale anomaly of the atmospheric electric field will produce the anomaly of electron concentration within the ionosphere. Ionospheric measurements presented in Figs. 10-12 confirm the presence of the ionospheric anomaly before the Colima earthquake.

\section{Discussion}

Different and independent data sources were used for analysis of the atmosphere and ionosphere variations around the time of the Colima M7.8 earthquake in Mexico on 21 January 2003. Their appearance and temporal evolution are synchronized in time and demonstrate a similar spatial distribution.
Following the presented physical mechanism and using the collected experimental data one can try to reconstruct the possible evolution of the atmosphere-ionosphere anomalies preceding the Colima earthquake. From the end of December 2003 the nighttime surface temperature increases in the area of the earthquake preparation (Fig. 7, red curve). One can associate this anomaly with the start of the possible radon anomaly (the heating starts in the surface ground layer). Then the radon appears in the near surface layer of the atmosphere and heating becomes noticeable in the daytime records of MODIS (from the first days of January 2003) and in the records of the local meteorological observatories (Fig. 7, orange curve), which manifests the local increase in the air temperature. The thermal air anomaly reaches its maximum at the middle of January, which is accompanied by the absolute monthly minimum of the relative air humidity. We should emphasise that the humidity drop can be produced only by the proposed mechanism of ionization. In the case of the heat coming from the underground, as proposed in some publications, the humidity should not drop but grow due to evaporation from the ground surface. The locality of the thermal anomaly and its close connection with the epicenter position of the impending earthquake is confirmed by the spatial temperature distribution on 14 January presented in Fig. 5. None of the possible meteorological processes can provide such a distribution of the ground air temperature. Recovery of the normal level of the air humidity after 15 January manifests the end of the radon anomaly (taking into account the semi-decay period of radon, it probably finished a few days earlier). The technology of the calculation of the SLHF derived from the satellite measurements (Schulz et al., 1997) shows that the main contribution to the SLHF makes 

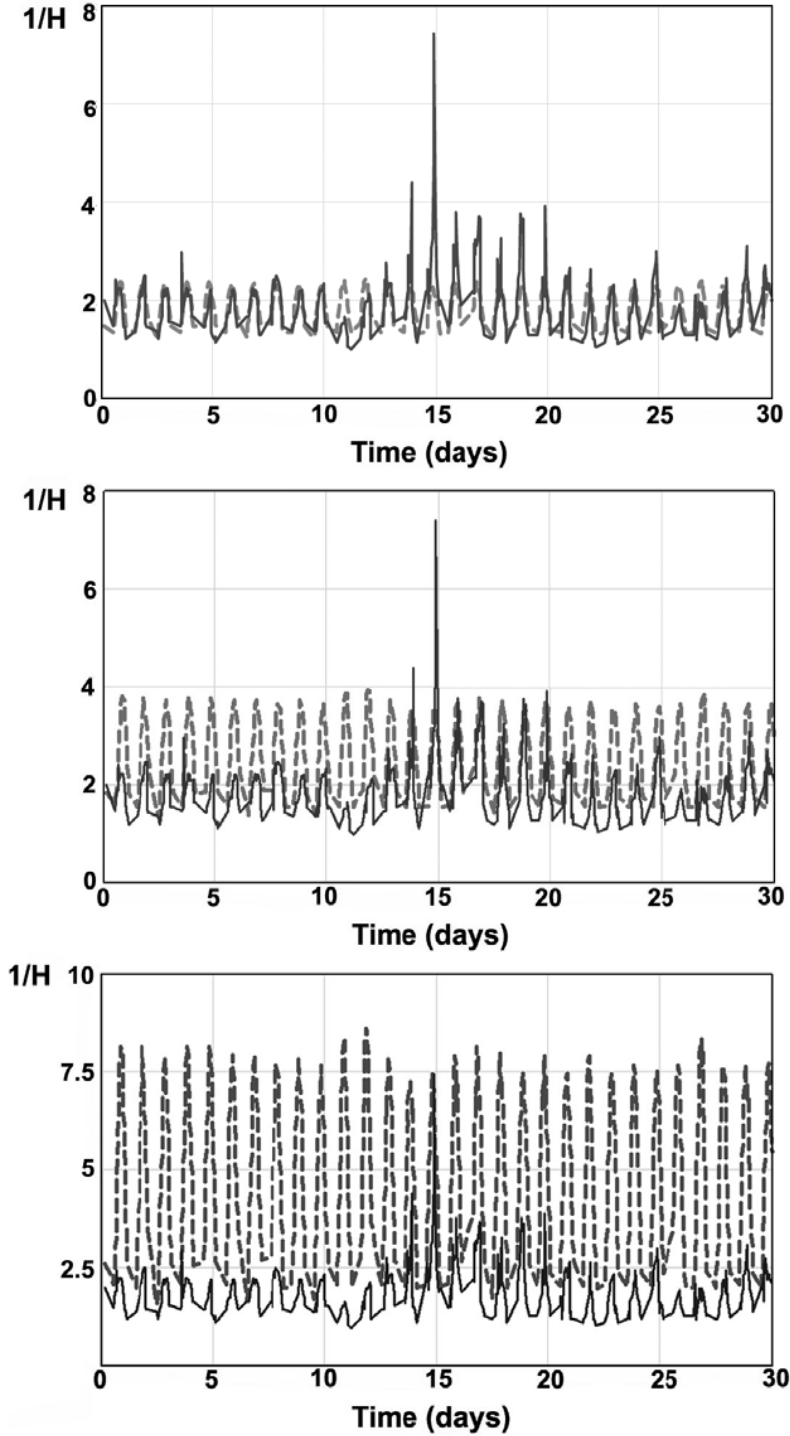

Fig. 14. Comparison of the reversed value of the experimentally measured relative humidity at Colima station (continuous line) and the reversed value of calculated relative humidity (dashed grey line). From top to bottom, calculated correction of $\Delta U=0.019 ; 0.022$ and $0.03 \mathrm{eV}$.

the increased humidity (which we observe in our data). This is why the anomalous fluxes of the SLHF are observed on 18 and 20 January (see Fig. 8). As it was shown by Pulinets and Boyarchuk (2004) and Boyarchuk et al. (2005), in the final stage of the ionization process, the large neutral clusters are formed as a result of Coulomb interaction between the clusters with positive and negative charges. After the end of the increased ionization they start to disrupt and a sharp increase in the charged particles leads to generation of the anomalous electric field practically simultaneously with the increase in the SLHF. This is why we observe the ionospheric anomaly at the same day as the SLHF anomaly, i.e. 18 January.

The lack of direct radon measurements around the time of the Colima earthquake puts forward a problem of organization of the regular radon monitoring at the Pacific coast of Mexico, due to the importance of this parameter in the presented model, and for the future detection of the possible precursory variations.

\section{Conclusion}

The complex analysis of the ground-based and satellite measurement data around the time of the Colima earthquake demonstrated that the observed variations of the atmosphere and ionosphere parameters have a common cause - the air ionization by radon. To improve the proposed model a more detailed and comprehensive set of ground-based and satellite measurements is necessary to check every element in the regarded chain of physical and chemical processes involved in the model of Lithosphere-Atmosphere-Ionosphere coupling.

Acknowledgements. This work was supported by the grants of PAPIIT IN 126002, CONACYT 40858-F and NASA 621-30-30-20. The authors thank the Mexican National Institute of Statistics, Geography and Informatics (INEGI) for providing the GPS data and would like to acknowledge the MODIS science Team and LP DAAC for making their data available to the user community.

Topical Editor U.-P. Hoppe thanks P. F. Biagi and another referee for their help in evaluating this paper.

\section{References}

Bandy, W. L., Hilde, T. W. C., and Yan, C.-Y.: The Rivera-Cocos plate boundary: Implications for Rivera-Cocos relative motion and plate fragmentation, Geological Soc. Amer., Special Paper, 334, 1-28, 2000.

Bering III, E. A., Few, A. A., and Benbrook, J. R.: The Global Electric Circuit, Physics Today, 51(10), 24-30, 1998.

Boyarchuk K. A., Karelin A. V., and Shirokov R. V.: Neutral cluster and its influence on electromagnetic effects in the atmosphere, Izvestiya Atmos. Oceanic Phys., 41, 487-497, 2005.

Bricard, J.: Action of radioactivity and pollution upon parameters of atmospheric electricity, in: Problems of atmospheric and space electricity, Proc. third int. conf. atmospheric and space electricity, Montreux, Switzerland, 5-10 May 1963, Elsevier Publishing Company, Amsterdam-London-New York, 82-117, 1965.

Cervone, G., Kafatos, M., Napoletani, D., and Singh, R. P.: Wavelet Maxima Curves Associated with Two Recent Greek Earthquakes, Nat. Hazards Earth Syst. Sci., 4, 359-374, 2004.

Cervone, G., Singh, R. P., Kafatos, M., and Yu, C.: Wavelet maxima curves of surface latent heat flux anomalies associated with Indian earthquakes, Nat. Hazards Earth Syst. Sci., 5, 87-99, 2005.

Ciraolo, L. and Spalla, P.: Comparison of ionospheric total electron content from the Navy Navigation Satellite System and the GPS, Radio Sci., 32, 1071-1080, 1997.

Dey, S. and Singh, R. P.: Surface latent heat flux as an earthquake precursor, Nat. Hazards Earth Syst. Sci., 3, 749-755, 2003. 
Dobrovolsky, I. R., Zubkov, S. I., and Myachkin, V. I.: Estimation of the size of earthquake preparation zones, Pageoph., 117, 1025-1044, 1979.

Inan, S.: Researches for possible earthquake precursor(s) in the Marmara region (NW Turkey), International Workshop "Early Warning Systems for Earthquake Monitoring by Using Space Technology", Istanbul, Turkey, 1-2 February, 2005.

Liu, J. Y., Chen, Y. I., Pulinets, S. A., Tsai, Y. B., and Chuo, Y. J.: Seismo-ionospheric signatures prior to $\mathrm{M} \geq 6.0$ Taiwan earthquakes, Geophys. Res. Lett., 27, 3113-3116, 2000.

Liu, J. Y., Chuo, Y. J., Shan, S. J., Tsai, Y. B., Pulinets, S. A., and Yu, S. B.: Pre-earthquake ionospheric anomalies monitored by GPS TEC, Ann. Geophys., 22, 1585-1593, 2004.

Mil'kis, M. R.: Meteorological Precursors of Strong Earthquakes, Izvestiya, Earth Physics, 22, 195-204, 1986.

Oliver, M. A. and Webster, R.: Kriging: a Method of Interpolation for Geographical Information Systems, Int. J. Geogr. Information Syst., 4, 313-318, 1990.

Ouzounov, D. and Freund, F.: Mid-infrared emission prior to strong earthquakes analyzed by remote sensing data, Adv. Space Res., 33, 268-273, 2004.

Pokhmelnykh, L. A.: Atmosphere electricity as a manifestation of the Earth-Sun interaction with the space, Appl. Phys., 4, 34-43, 2003.

Prasad, B. S. N., Nagaraja, T. K., Chandrashekara, M. S., Paramesh, L., and Madhava, M. S.: Diurnal and seasonal variations of radioactivity and electrical conductivity near the surface for a continental location Mysore, India, Atmos. Res., 76, 65-77, 2005.

Pulinets, S. A.: Seismic activity as a source of the ionospheric variability, Adv. Space Res., 22, 903-906, 1998.

Pulinets, S. A.: Ionospheric precursors of earthquakes. Recent advances in theory and practical applications, Terr., Atmos. Ocean Sci., 15, 413-435, 2004.

Pulinets, S. A. and Boyarchuk, K. A.: Ionospheric Precursors of Earthquakes, Springer, Berlin, Heidelberg, New York, 316 p., 2004.

Pulinets, S. A., Boyarchuk, K. A., Hegai, V. V., Kim, V. P., and Lomonosov, A. M.: Quasielectrostatic Model of AtmosphereThermosphere-Ionosphere Coupling, Adv. Space Res., 26, 8, 1209-1218, 2000.

Pulinets, S. A., Legen'ka, A. D., Gaivoronskaya, T. V., and Depuev, V. K.: Main phenomenological features of ionospheric precursors of strong earthquakes, J. Atmos. Solar-Terr. Phys., 65, 13371347, 2003.

Pulinets, S. A., Gaivoronska, T. B., Leyva Contreras, A., and Ciraolo, L.: Correlation analysis technique revealing ionospheric precursors of earthquakes, Nat. Hazards Earth Syst. Sci., 4, 697$702,2004$.
Pulinets, S. A., Leyva, A., and Ciraolo, L.: GPS TEC variations around the time of the Colima earthquake of 21 January 2003, Geofisica Internacional, 369-377, 2005.

Pulinets S. A., Ouzounov, D., Karelin, A. V., Boyarchuk, K. A., and Pokhmelnykh, L. A.: The physical nature of thermal anomalies observed before strong earthquakes, Physics and Chemistry of the Earth, 31, in press, 2006.

Roble, R. G. and Tzur, I.: The Global Atmospheric-Electrical Circuit, in: The Earth's Electrical Environment, Studies in Geophysics series, National Academy Press, Washington D.C., 206231, 1986.

Schulz, J., Meywerk, J., Ewald, S., and Schlussel, P.: Evaluation of satellite-derived Latent Heat Fluxes, J. Climate, 10, 2782-2795, 1997.

Sedunov, Y. S., Volnovitskii, O. A., Petrov, N. N., Reitenbakh, R. G., Smirnov, V. I., and Chernikov, A. A.: Atmosphere, Handbook (Reference data and Models) (In Russian), Gidrometeoizdat, Leningrad, 1997.

Segovia, N., Pulinets, S. A., Leyva, A., Mena, M., Monnin, M., Camacho, M. E., Ponciano, M. G., and Fernandez, V.: Ground radon exhalation, an electrostatic contribution for upper atmospheric layers processes, Radiat. Measurements, 40, 670-672, 2005.

Singh, S. K., Pacheco, J. F., Alcántara, L., Reyes, G., Ordaz, M., Iglesias, A., Alcocer, S. M., Gutierrez, C., Valdés, C., Kostoglodov, V., Reyes, C., Mikumo, T., Quaas, R., and Anderson, J. G.: A Preliminary Report on the Tecomán, Mexico Earthquake of 22 January 2003 (Mw7.4), Seism. Res. Lett., 74, 279-289, 2003.

Stull, R.: Introduction to Boundary Layer Meteorology, Kluwer Academic Publ., Heidelberg, 313-316, 1988.

Toutain, J.-P. and Baubron, J.-C.: Gas geochemistry and seismotectonics: a review, Tectonophysics, 304, 1-27, 1998.

Tramutoli, V., Di Bello, G., Pergola, N., and Piscitelli, S.: Robust satellite techniques for remote sensing of seismically active areas, Annali de Geofisica, 44, 295-312, 2001.

Tramutoli, V., Cuomo, V., Filizzola C., Pergola, N., and Pietrapertosa, C.: Assessing the potential of thermal infrared satellite surveys for monitoring seismically active areas. The case of Kocaeli (Izmit) earthquake, 17 August 1999, Remote Sens. Environ., 96(3-4), 409-426, 2005.

Tronin, A. A., Hayakawa, M., and Molchanov, O. A.: Thermal IR satellite data application for earthquake research in Japan and China, J. Geodyn., 33, 519-534, 2002.

Wilding, R. J. and Harrison, R. G.: Aerosol modulation of small ion growth in coastal air, Atmos. Environ., 39, 5876-5883, 2005. 